\title{
Area Studies and the Challenges of Creating a Space for Public Debate
}

Beth Buggenhagen

Scholarship in the African humanities — art history, cultural anthropology, history, literature, religion, and so forth - has transcended disciplinary ways of knowing, transformed scholarly conversations from a focus on difference between Africa and the West to an emphasis on connections and convergence, and emphasized the universality of the particular. Today, the African humanities must confront another limitation in scholarly discourse about Africa: the presentist priorities of schools of global studies. If it appears that claims to particularistic knowledge of social and historical processes and linguistic competence are falling on deaf ears, it may be because the logic of securing "America's Place in the World," the topic of the spring 2016 symposium in the School of Global and International Studies at Indiana University, no longer depends on knowledge of cultural processes produced by academics based in the university system. The United States moved on in the fall of 2014 from cultural tactics such as the Human Terrain Systems (HTS), developed by the US Army in 2006, to technical interventions like drones - interventions that do not rely on human sentiment or error, and big data like computational social sciences and predictive modeling (Gezari 2015). HTS embedded anthropologists (though the major scholarly association, the American Anthropological Association, rightly opposed HTS) and other social scientists with military units to provide regional expertise and cultural knowledge to aid military intelligence gathering and policymaking. In this new climate, dominated by technological solutions to social and political problems, largely managed by the Department of Defense, how can scholars of the African humanities based in the university system continue to make a case for the knowledge that we produce, which prioritizes humanistic understanding and humane values? It is these values, I argue, that foster public debate on the central issues of our time.

If, as Mamadou Diouf argued at the symposium "African Studies and the Challenge of the Global in the $21^{\text {st }}$ Century" at Indiana University, also in the spring of 2016, the problem of African studies in Africa was its reception among continent-based scholars as imperialist knowledge, then what can we possibly make of the securitization of African studies in the United States at present? Is this not part of the reason that the area-based humanities fields are now in a school of global studies? For example, the African studies program at Indiana University has been moved into the newly formed School of Global and International Studies. Africa is no longer a 
backwater in the foreign-service world: it is a frontline in the war on terror, as attacks over the past year in Mali, Côte d'Ivoire, and Burkina Faso reveal. Scholars in the African humanities have good reason to be concerned about the instrumentalization of area studies for defense priorities. Our work provides legitimacy for defense-oriented projects. As Judith Byfield argued at our spring symposium, geopolitics cannot be the engine that drives knowledge production about Africa.

If it seems as if scholars of the African humanities in schools of global studies concerned with "America's Place in the World" have no seat at the table, then such a perspective is at odds with current directions in federal spending on culture. As James Pritchett, a past president of the African Studies Association, argued, culture matters; if not, the federal government would not be pouring money into the production of cultural knowledge. As Pritchett has argued, Title VI has not been reduced "by nearly $\$ 56$ billion annually in the last three years alone" because culture is irrelevant. In fact, this decline has happened in tandem with an increase in "federal funds to military managed programs of language and cultural studies," largely orchestrated by the Department of Defense. He enumerates the following examples:

The Defense Language Institute, Foreign Language Center (DLIFLC) in Monterey, California[,] receives nearly $\$ 345$ million annually, over four times the funding provided to the 125 Title VI Centers combined. The Human Terrain System (HTS), an army program that employs social scientists to provide the military with cultural knowledge[,] has an annual budget of $\$ 150$ million. AFRICOM's new Socio-Cultural Research Advisory Team (SCRAT), a robust crew of deployable ethnographers, and the newly formed AFRICOM Social Science Research Center (SSRC) will absorb millions more. These, along with the Minerva Project and the various Boren and National Security Education Programs (NSEP) stand as clear evidence that to the US federal government, culture does indeed matter. (Pritchett 2014) ${ }^{1}$

Thus, it is not that culture no longer matters, but that dollars are being shifted from the Department of Education to the Department of Defense. As the money shifted from one federal entity to another, university-based scholars' opportunities to push public debate in these new directions have been strangled by financial crises at the level of the university. Amid these constraints and conditions, how do scholars continue to make a case for their interventions? 
Here is what the African humanities can contribute that defense-based institutions cannot: a perspective on the global that cannot be anticipated and that is unfolding at a pace faster than slow-moving federal bureaucracies with idiosyncratic spending priorities can grasp; yet universities can also be conservative institutions. With increasingly market-based models of educational administration, faculty research is geared toward garnering funding targeted to answer preexisting problems, often outcomes where a profit or a patent is anticipated. And schools of global studies follow the defense money, hollowing out traditional disciplines like anthropology, history, and comparative literature based in particularistic knowledge of a place and time. As James Delehanty argued at our symposium, it is the problem of money underpinned by the problem of marketization of universities: chasing money, rather than driving research. The African humanities is well placed to produce knowledge to drive policy agendas, rather than responding to them. When given the space and the time to prioritize research that yields innovative insights, we put in place the kinds of data and understanding necessary, should a crisis erupt because our expertise has been cultivated over the long term.

Yet to figure out what the problems are through the research process - to build a body of knowledge to answer questions that cannot be anticipated - has always been a priority of the African humanities. When Libya fell, academia did not have to train a new generation of scholars with knowledge of the region to understand the resulting conflict in northern Mali as arms and Islamist reform movements bled into the region: scholars were already in place, providing eyewitness accounts and safeguarding the knowledge held in world heritage sites, like the libraries of Timbuktu.

But humanities scholars' long-term views and the realities of a rigorous approach require time- - which conflicts with the presentism of global schools, as Judith Byfield argued at our symposium. Even when scholars of Africa bring their expertise to bear on a momentary crisis, like Boko Haram, for example, they not only provide the larger context through which we can understand these moments of rupture, but lay the groundwork for archiving the present; rather than skipping from hot spot to hot spot, dropping in on and exiting from particular places, scholarly work continues to unfold in these places over time. In fact, my coauthors, Anne-Maria Makhulu and Stephen Jackson, have made such an argument to shift discourse about state and society in Africa away from its pervasive notion of crisis to focus on the everyday lives of ordinary women and men in contexts of volatility over the "long durée" that characterizes the 
African continent (Makhulu, Buggenhagen, and Jackson 2010), so that when the next so-called crisis erupts, the scholarly work has already been set in place to understand these events. What public universities like Indiana University can do to support humanistic knowledge is to be sure it reaches the widest public audience. Carina Ray, an historian at Fordham University, who visited the IU African studies program in spring 2016, has argued that universities have a "responsibility to be of wider service to the public," and to support the work of its scholars in "intervening in and shaping the most crucial conversations of our time" (Ray 2016:22). Ray argued that as scholars of the humanities seek to write for diverse audiences beyond the academy, universities ought to adjust criteria for tenure and promotion. This might be one outcome of the global turn for humanities scholars.

As Judith Byfield argued at our spring symposium, one problem we face is the value of patents to the university, and I would add the attractiveness of Defense Department funding focused on culture, but the market is only one measure of value. Though it may be the most dominant form of value in our time, a humane and humanistic approach to knowledge can produce other values (Graeber 2001).

If there is a space for the African humanities, focused on the humanistic production of knowledge, in schools of global studies (and I think there is), what might it look like, and what might it yield? As Mamadou Diouf asked at our symposium, how can we capture and represent the most innovative connections between research on Africa and the production of scholarly knowledge? The arts and humanities are on the cutting edge of grappling with transformations wrought by global capital. The humanities not only value critical and analytical thinking necessary to democratic practice and citizenship, but promote ethical values: they ground national and international discourse, often characterized by polarizing views, in enduring human values. The prominent role of technological solutions, like the drones and big data that I mentioned earlier, raise ethnical questions that require public discourse. Humanities scholarship provides the knowledge to address these questions.

In my own field of anthropology, it has been argued that Africa has long served as raw material for disciplinary theorizing about universals (Comaroff and Comaroff 2011). Indeed, at our symposium, Judith Byfield mentioned that Africa is often acted upon. Certainly this appears to be the model embraced by global schools - that area studies produce the raw data for defense interventions. As an anthropologist. I approach research as an iterative endeavor, constantly to 
reframe my scholarly questions in relation to what people are asking themselves about their own social worlds; these are questions that can be gotten at only through field-based research. Fieldwork is a transformative experience, which happens only when we listen and are willing to question ourselves. It is inherently collaborative and participatory-which cuts across the grain of global schools and discourses about "America's place in the world."

At Indiana University, a multidisciplinary group of scholars have formed a collective called New Media and Literary Initiatives in Africa (NEMLIA). We see cultural producers as sitting on the cutting edge, providing some of the most cogent critiques of the place of Africa in the global and the global in Africa. The problem with scholarship is that it always lags behind events unfolding in the world, and thus raises the question of how we theorize as the ground beneath us shifts (Mbembe n.d.). One answer to that question is to look at how actors on the ground are grappling with these questions. Here, I will mention the work of two cultural figures that NEMLIA hosted in the past couple of years, the filmmaker Joseph Gai Ramaka and the photographer Omar Victor Diop.

Joseph Gaï Ramaka's series of animated shorts addresses global security from a different angle, the threat of environmental catastrophe - from our reliance on electricity and plastics, from our waste practices, from the construction boom and its environmental impact, and from deforestation. These stories are narrated from Africa's westernmost peninsula, Senegal, but the depth of ecological devastation in this country on the edge of the Sahel is a forerunner of things to come (Comaroff and Comaroff 2011). Perhaps capitalism emerges in an extreme form here because of its colonial history of monocropping, mining, and deforestation, characteristic of extractive economies. You have what appears as the buildup of the economy, concretized through a construction boom and the paving of streets, but against this backdrop of growth is the casualization of work through ever-increasing forms of informality and extemporization, improvisational housing arrangements, and the like. Is this a building up, or is it a breakdown? Ramaka's animated shorts, Plastiig, Fippu, Ceeb u mbalit, L'Arbe qui crie, and Dakar Verdure were made with young Senegalese animators as part of his projects 1000 Flashdrives for the Environment and E-Book Africa, which address environmental themes aimed at young people to raise their awareness. E-book Africa addresses the need for a platform to distribute digital materials. Ramaka's work on the environment sensitizes his audience and provides a language with which to speak about environmental issues encountered in their everyday lives, the 
landscape, and the built environment. Ramaka is a cultural producer who seeks to render these terms useful for clarifying the everyday experiences of those who seek to ameliorate the conditions of their lives — prevent their homes from flooding, prevent the swarming of mosquitos that carry malaria around the waste water that is dumped from homes into the street, and so forth. These films are about African self-imaging, as well as Senegalese filmmakers, writers, producers who make for a Senegalese audience, for wider audiences, a window into questions that people are asking themselves about their own social, environmental, and political worlds. They are highly successful, perhaps revealing how "old margins are becoming new frontiers" (Comaroff and Comaroff 2011:13).

Omar Victor Diop, a Dakar-based photographer, recently shared his body of work Refugee with NEMLIA. Refugee is part of a collaborative project between the Annenberg Foundation and the UN Higher Commission for Refugees. The exhibition, of which Diop's work is a part, illustrates the problem of forced displacement through the lens of some of the world's most distinguished photographers. Drawing on the portraiture tradition in West Africa, Diop created portraits of Mbororo women and men who had fled the Central African Republic and were residing in refugee camps in Cameroon. His digital photographic portraits of individuals and families draw on the aesthetics of commemorative cloth. Rather than show the suffering of the recent wave of migration on and off of the African continent, Diop sought to restore the dignity of his sitters and to humanize refugees.

In sum, what can we make of the African humanities and the global turn, and how can we turn back the potential homogenizing agendas of global studies schools of study? Mamadou Diouf offered one suggestion at our symposium: while remaining committed to a global focus, a regional perspective is "essential to preserving the particularity of difference within potentially homogenizing global agenda," and "each region brings a unique set of impulses, experiences, and knowledges to bear on global issues." Certainly, the African humanities reveal much about African societies and their engagements with the world. What the African humanities can do (as Carina Ray has argued) that defense institutes cannot is marshal our knowledge to foster public debate on some of the central issues of our time.

\section{REFERENCES CITED}

Comaroff, Jean, and Comaroff, John. 2011. Theory From the South: Or How Euro-America Is Evolving Toward the South. Routledge. 
Gezari, Vanessa. 2015. The Quiet Demise of the Army's Plan to Understand Afghanistan and Iraq. New York Times Magazine, August 18.

Graeber, David. 2001. Toward an Anthropological Theory of Value. New York: Palgrave.

Makhulu, Anne-Maria, Beth Buggenhagen, and Stephen Jackson. 2010. Hard Work, Hard

Times: Global Volatility and African Subjectivities. Berkeley: University of California Press.

Mbembe, Achille. N.d. Theory from the Antipodes: Notes on Jean and John Comaroff's Theory from the South. Cultural Anthropology. https://culanth.org/fieldsights/272-theory-fromthe-antipodes-notes-on-jean-john-comaroffs-tfs.

Pritchett, James. 2014. Response: Funding Challenges and Opportunities in African Studies Research. African Studies Association News.

Ray, Carina. 2016. Tales from the New African Archive. Historical Reflections 38(2): 13-24.

${ }^{1}$ Although the HTS did largely decline after 2014, as I mention at the beginning of my piece, the other programs Pritchett mentions have continued to be funded. 